\title{
Correction to: Oxidizable Phenolic Concentrations Do Not Affect Development and Survival of Paropsis Atomaria Larvae Eating Eucalyptus Foliage
}

\author{
Karen J. Marsh ${ }^{1}$ • Wufeng Zhou ${ }^{1} \cdot$ Hannah J. Wigley ${ }^{1} \cdot$ Ian Wallis $^{1} \cdot$ William J. Foley $^{1}$
}

Published online: 5 October 2017

(C) Springer Science+Business Media, LLC 2017

Correction to: J Chem Ecol

https://doi.org/10.1007/s10886-017-0835-y

Ian Wallis was inadvertently omitted as an author in this study. Ian Wallis assisted with the collection of the leaf samples that were used in this study, and built the chambers that the insects were housed in. He also assisted with the supervision of Wufgeng Zhou and Hannah Wigley during the project. All co-authors agree with the addition of Ian Wallis to the authorship of this article.

The corrected citation should be:

Marsh KJ, Zhou W, Wigley HJ, Wallis, I, and Foley WJ (2017) Oxidizable phenolic concentrations do not affect development and survival of Paropsis atomaria larvae eating Eucalyptus foliage. Journal of Chemical Ecology 43:411421. https://doi.org/10.1007/s10886-017-0835-y

The online version of the original article can be found at https://doi.org/ 10.1007/s10886-017-0835-y.

Karen J. Marsh

karen.marsh@anu.edu.au

1 Research School of Biology, The Australian National University, ACT, Canberra 2601, Australia 